\title{
Cost-Utility Analysis of Deferiprone for the Treatment of $\beta$-Thalassaemia Patients with Chronic Iron Overload: A UK Perspective
}

\author{
Anthony Bentley $\cdot$ Samantha Gillard $\cdot$ \\ Michael Spino $\cdot$ John Connelly $\cdot$ Fernando Tricta
}

Published online: 20 July 2013

(c) The Author(s) 2013. This article is published with open access at Springerlink.com

\begin{abstract}
Background Patients with $\beta$-thalassaemia major experience chronic iron overload due to regular blood transfusions. Chronic iron overload can be treated using iron-chelating therapies such as desferrioxamine (DFO), deferiprone (DFP) and deferasirox (DFX) monotherapy, or DFO-DFP combination therapy.

Objectives This study evaluated the relative cost effectiveness of these regimens over a 5-year timeframe from a
\end{abstract}

Electronic supplementary material The online version of this article (doi:10.1007/s40273-013-0076-z) contains supplementary material, which is available to authorized users.

A. Bentley $(\bowtie) \cdot$ S. Gillard

Abacus International, 6 Talisman Business Centre,

Talisman Road, Bicester, Oxfordshire OX26 6HR, UK

e-mail: abentley@abacusint.com;

anthony.bentley@abacusint.com

M. Spino $\cdot$ J. Connelly $\cdot$ F. Tricta

ApoPharma Inc., 200 Barmac Drive, Toronto M9L 227, Canada

M. Spino

Leslie Dan Faculty of Pharmacy, University of Toronto,

Toronto, Canada
UK National Health Service (NHS) perspective, including personal and social services.

Methods A Markov model was constructed to evaluate the cost effectiveness of the treatment regimens over 5 years. Based on published randomized controlled trial evidence, it was assumed that all four treatment regimens had a comparable effect on serum ferritin concentration (SFC) and liver iron concentration (LIC), and that DFP was more effective for reducing cardiac morbidity and mortality. Published utility scores for route of administration were used, with subcutaneously administered DFO assumed to incur a greater quality of life $(\mathrm{QoL})$ burden than the oral chelators DFP and DFX. Healthcare resource use, drug costs (2010/2011 costs), and utilities associated with adverse events were also considered, with the effect of varying all parameters assessed in sensitivity analysis. Incremental costs and quality-adjusted life-years (QALYs) were calculated for each treatment, with cost effectiveness expressed as incremental cost per QALY. Assumptions that DFP conferred no cardiac morbidity, mortality, or morbidity and mortality benefit were also explored in scenario analysis.

Results DFP was the dominant strategy in all scenarios modelled, providing greater QALY gains at a lower cost. Sensitivity analysis showed that DFP dominated all other treatments unless the QoL burden associated with the route of administration was greater for DFP than for DFO, which is unlikely to be the case. DFP had $>99 \%$ likelihood of being cost effective against all comparators at a willingness-to-pay threshold of $£ 20,000$ per QALY.

Conclusions In this analysis, DFP appeared to be the most cost-effective treatment available for managing chronic iron overload in $\beta$-thalassaemia patients. Use of DFP in these patients could therefore result in substantial cost savings. 


\section{Key Points for Decision Makers}

- Deferiprone (DFP) is the dominant treatment strategy for removal of excess iron in $\beta$-thalassaemia patients in the base case, meaning that it provides additional benefits over comparator treatments at a cost saving to the NHS.

- DFP remains the dominant strategy against all comparators in a number of different modelling scenarios, in which it is assumed that DFP significantly reduces cardiac morbidity only, significantly reduces cardiac mortality only, or confers no cardiac benefit.

- Probabilistic sensitivity analysis demonstrates that, at a willingness-to-pay threshold of $£ 20,000$ per QALY, DFP has a $>99 \%$ likelihood of being cost effective against all comparators.

\section{Introduction}

Thalassaemia is one of the most common genetic diseases worldwide, with approximately 60,000 severely affected children born each year [1]. Children born with the $\beta$-thalassaemia major form of the disease suffer chronic severe anaemia and require blood transfusions every 2-4 weeks to sustain life [2-5]. It has been estimated that this form of the disease affects 1 in 100,000 of the UK population [3], and that approximately 700 patients with $\beta$-thalassaemia major were alive in the UK in 2003 [6]. As a result of repeated transfusions, these patients accumulate iron at a rate of $0.3-0.5 \mathrm{mg} / \mathrm{kg}$ per day. This results in a $60 \mathrm{~kg}$ person adding 6.6-11.0 g of extra iron per year every year for the rest of their life. In contrast, healthy adults have stable iron stores of around 3-4 g [7]. Beta-thalassaemia major patients receiving regular transfusions are consequently at risk of iron overload, which can cause hypogonadism, hypothyroidism, diabetes mellitus, liver dysfunction and heart dysfunction $[8,9]$. If left untreated, patients are at risk of premature death in adolescence or young adulthood, mainly due to iron-induced cardiac disease [10].

The standard treatment for transfusional iron overload is chelation therapy, which has significantly reduced mortality since the introduction of desferrioxamine (DFO) in the 1960s [11]. However, DFO is administered as a subcutaneous (SC) infusion over 8-12 hours, 5-7 days per week [12]. This can have a significant impact on patients' quality of life (QoL) [13] and sets younger patients apart from their peers $[5,13]$; adherence to the DFO infusion schedule is therefore often resisted, significantly increasing patients' risk of cardiac disease [14]. Oral chelation therapy has subsequently been developed in order to ease the treatment burden associated with iron chelation, and therefore increase patient compliance. The introduction of the first oral chelator, deferiprone (DFP), in 1999 [15] resulted in improved patient survival $[6,16]$, while deferasirox (DFX) was licensed in 2006 [17].

When used as monotherapy, each of DFO, DFP and DFX have been shown to produce reductions in serum ferritin concentration (SFC) and liver iron concentration (LIC) [18-21]; however, these measures of total body iron are not effective in predicting heart failure, the most serious consequence of iron toxicity. For this outcome, it has been found that cardiac iron levels, as measured by cardiac MRI T2*, have the greatest predictive value [22]. DFP has been demonstrated to be superior to DFO in reducing cardiac iron levels, and in improving cardiac function as assessed by left and right ventricular ejection fraction (LVEF and RVEF, respectively) [16, 19-21]. This is an important finding, as improvements in LVEF have been shown to significantly reduce the risk of future heart failure [23]. DFP may also be used as a combination therapy with DFO, which has been shown to significantly improve SFC, LIC, cardiac MRI T2* and cardiac function, compared with DFO alone [24-26]. DFX is contraindicated for use in combination therapy [17].

The licensed indication for DFP in Europe is for patients in whom DFO therapy is contraindicated or inadequate [15]; however, use of DFP in monotherapy or in combination with DFO is widespread. This is likely due to several factors, including the inadequacy of DFO in controlling body iron load in some patients [27]; the significant QoL burden associated with its daily administration $[13,28]$; and the superiority of DFP to DFO in reducing heart disease and/or increasing survival [15]. The combination of DFO and DFP has the added advantage of a more pronounced reduction of serum ferritin and liver iron concentrations than DFO monotherapy [25].

With four treatment regimens available with differing abilities to remove excess iron, different prices, and different treatment burdens, the relative cost effectiveness of these treatments is highly relevant when considering which treatment to prescribe. Previous economic evaluations have focused on DFO and DFX, and have reported that DFX is cost effective compared with DFO, although none have used published adverse event (AE) rates [3, 28, 29]. However, DFP has been included in cost-effectiveness analysis in only one study, from a Thai perspective, which did not consider combination therapy [30]. While this study found that DFP was cost effective compared with DFX and DFO, the lack of a full economic evaluation of all available treatment regimens from an EU member state with significant use of the relevant chelators (for example, the UK) to guide a European perspective may hinder decision makers. 
This study consequently considers the cost effectiveness of DFO, DFP and DFX monotherapy, and combination therapy, from a UK perspective, using a full economic model which incorporates published treatment-related $\mathrm{AE}$ rates. The effect of varying all parameters used within the model was evaluated in sensitivity analysis.

\section{Methods: Systematic Review}

Systematic reviews were conducted to identify randomized controlled trial (RCT) and non-RCT characteristics of iron chelation with each treatment, and quality of life in patients receiving chelation therapy. Searches were conducted in The Cochrane Library, OVID MEDLINE (including MEDLINE In-process) and OVID Embase on 9 February 2011, with no restrictions on date. Using Boolean operators, the searches combined terms (including MeSH headings as appropriate) for the condition, the treatments and the outcomes of interest. This was supplemented by hand searching of the following conference proceedings from the years 2008 to 2010: American Society for Hematology; European Haematology Association Congress; UK Thalassaemia Society; Thalassaemia International Conference; British Society for Haematology Annual Scientific Meeting; Caribbean Health Research Council Meetings; and the National Sickle Cell Disease Program Annual Meeting. Identified studies were independently assessed by two reviewers in order to confirm that they met the pre-defined inclusion/ exclusion criteria and any discrepancies were resolved by a third party (see Acknowledgments). Each reviewer's documents were checked by the second reviewer to ensure quality and any inconsistencies were resolved through discussion. The inclusion criteria for the systematic review were: population-thalassaemia patients with chronic iron overload requiring blood transfusions; intervention-DFP, DFO, DFX or combination therapy; study design-RCT, prospective, or observational studies; outcomes-SFC, LIC, cardiac MRI T2*, total iron excretion, mortality or AEs. Full details of the systematic review are available in the electronic supplementary material.

\section{Results: Systematic Review}

A total of 4,053 publications were screened, based on their title and abstract. From these, the full texts of 69 publications were evaluated, which yielded 11 relevant RCTs [18, 19, 25, 31-38] and 9 non-RCTs [16, 20, 21, 39-44]. These publications were used to identify potential data inputs for the model.

\section{Methods: Economic Model}

\subsection{Outline of the Economic Model}

\subsubsection{Population, Perspective, and Comparators}

The model considered adults and children, regardless of treatment history or disease status, with transfusiondependent $\beta$-thalassaemia receiving iron chelation therapy for chronic iron overload. The model used a UK National Health Service (NHS) perspective (including personal and social services), in line with UK health technology appraisal (HTA) guidelines [45]. A societal perspective was not used due to a lack of data on productivity gains/ losses or absenteeism with the available treatment regimens. The comparators considered were DFO, DFX and DFP monotherapy, and combination therapy with DFODFP, with discounting at $3.5 \%$ in line with guidance from the UK Treasury [46].

\subsubsection{Base Case}

The base case for the model was a 5-year Markov-type model using an annual cycle where it was assumed that DFP-containing regimens confer an incremental benefit to patients in terms of cardiac morbidity and mortality over DFO or DFX monotherapy. A Markov structure was used based on the relevant clinical data (cardiac mortality and morbidity); this structure has been used in previous economic evaluations of iron chelation regimens [29, 30]. An annual cycle was chosen given the availability of annual mortality data; such a cycle has also previously been used in economic evaluations of iron chelation regimens [28]. Five years was chosen as the time horizon as this reflects the duration of the clinical trials from which the data on morbidity and mortality were derived. Model calculations were verified by a local health economist and model assumptions by two consultant haematologists and one consultant nephrologist.

\subsubsection{Scenarios Considered}

The cardiac benefit in morbidity and mortality of DFP over DFX is an assumption based on the available evidence (see Sect. 4.2.1); three alternative efficacy-based scenarios were therefore also considered using Markov-type models: the base case excluding a cardiac morbidity benefit but maintaining the mortality benefit over 5 years (Scenario 1) (Fig. 1); the base case excluding a cardiac mortality benefit but maintaining the cardiac morbidity benefit over 5 years (Scenario 2); and a 1-year Markov-type model where all treatments are assumed to have an equal effect on cardiac morbidity and mortality (Scenario 3). The 1-year approach 

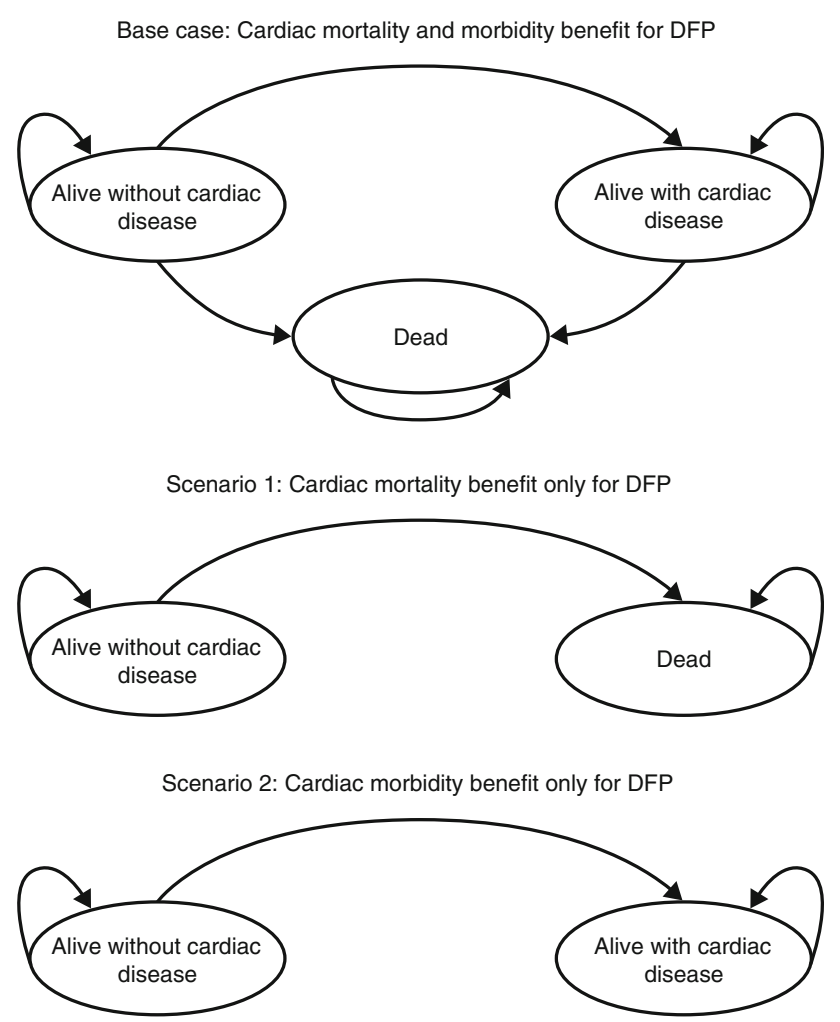

Fig. 1 Schematics of the Markov model used for each scenario. No schematic is shown for Scenario 3, as in this scenario the patient is alive without cardiac disease and remains in this state. DFP deferiprone

is used in Scenario 3 as this is consistent with other economic evaluations which have assumed equal efficacy for all treatments $[3,28]$. As DFO patients may receive treatment via a battery-operated pump instead of a balloon infuser, a scenario was also considered where all DFO and combination therapy patients received treatment via a pump (Scenario 4).

\subsubsection{Model Outcomes}

The model calculated costs and quality-adjusted life years (QALYs) for each treatment regimen based on the cost of the regimen, the relative effect on cardiac morbidity and mortality, the associated AEs and the utilities associated with their route of administration. Cost per QALY was chosen as the primary outcome as this accounts for the quality and quantity of the health gain from a treatment regimen, as well as the impact of that treatment regimen upon patients' quality of life.

\subsubsection{Model Inputs and Assumptions}

The data used to inform the model were obtained from a systematic review of the literature and other relevant data sources. The assumptions used in the model are given in Table 1.

\subsection{Data Used in the Model}

\subsubsection{Efficacy}

A review of the results of the trials identified by the systematic review showed that DFO and DFP have a similar effect on SFC and LIC [18, 19], and that DFO and DFX ${ }^{1}$ also produce equivalent results for these outcomes [31, 38]. Given the absence of RCTs directly comparing DFP and DFX, it was assumed that DFP and DFX had an equivalent effect on these outcomes, based on the equivalence of each to DFO [18, 19, 31].

In the absence of direct evidence of the effect of a drug on cardiac morbidity and mortality, cardiac MRI T2* was used as a proxy. The relative risk (RR) of heart failure or arrhythmia has been shown to increase linearly as $\mathrm{T} 2 *$ times decrease from $20 \mathrm{~ms}$ [22]. Patients with a T2* $<6 \mathrm{~ms}$ consequently have a RR of heart failure of 270 , and a RR of arrhythmia of 8.79 , compared with $\mathrm{T}^{*} \geq 20 \mathrm{~ms}$ [22]. DFO and DFX have been shown to have a similar effect on this outcome in observational studies [20,21], and were therefore assumed to have an equivalent effect on cardiac mortality and morbidity. DFP-containing regimens (DFP monotherapy and combination therapy) were found to improve cardiac outcomes, compared with DFO monotherapy [16, 19-21]. As only one RCT reported mortality for DFP monotherapy, data from the multi-centre, openlabel trial in 144 patients by Maggio et al. [34] were used to model cardiac mortality. No RCTs reported on morbidity for DFP; a retrospective analysis in 129 patients by Piga et al. [43] comparing DFP with DFO was therefore used to model cardiac morbidity. The data from Piga et al. for this outcome are consistent with those from another observational study by Borgna-Pignatti et al. [16].

Maggio et al. reported no deaths in the DFP and combination therapy groups, and $4.8 \%$ cardiac mortality in the DFO group over 5 years, while Piga et al. reported $4 \%$ morbidity in the DFP group and $21 \%$ in the DFO group over 5 years. These were converted into an annual rate for use in the model using actuarial life-table methods ${ }^{2}$ [47].

\footnotetext{
1 The registration trial for DFX failed to meet the primary endpoint of maintenance or reduction of LIC; however, this was attributed to the fact that patients received proportionally lower doses of DFX relative to DFO. The authors conclude that there was a clear demonstration of iron excretion related to the dose administered [31].

2 Data were adjusted for use in the model by converting the 5-year probability of the event into a 5-year rate, which was then adjusted to an annual rate and converted back into an annual probability. This is achieved using the following formula: $1-\operatorname{EXP}(-(-\mathrm{LN}(1-$ (Probability of event over time period considered, $X)) /($ Time period considered, $X /$ Time period required, $Y)$ )).
} 
Table 1 Assumptions used in the model

Patient weight of $63 \mathrm{~kg}$, based on the average weight for men and women calculated from the British National Formulary and varied within the sensitivity analysis to account for a spectrum of child and adult weights [56]. This weight is consistent with the average patient weight from US DFP patient registries of $62 \mathrm{~kg}$ [57]

Dosing was assumed to be from the mid-range of the product SPCs, based on the input of two consultant haematologists and one consultant nephrologist. The impact of alternative dosing was considered in sensitivity analysis

Patients who developed cardiac disease were conservatively assumed to have NYHA grade I disease and no incremental costs were considered

The cost of managing thalassaemia was assumed to be the same for all treatment regimens and was therefore not accounted for in the model

All iron chelation regimens are assumed to have an equivalent effect on SFC and LIC. Given the difficulty in correlating these outcomes with morbidity and mortality, this assumption was not varied in sensitivity analysis

Due to a lack of data regarding the efficacy of DFX in cardiac morbidity and mortality, it was assumed that the rates of cardiac events (including deaths with DFX) are the same as for DFO. Data on cardiac T2* for DFO and DFX were used as a proxy to establish equivalence of the treatments

As morbidity and mortality data are taken from separate studies, the risk of death in both alive health states was considered to be equal The utility value for DFP administration was assumed to be equal to that for DFX based on oral administration dosing regimens

While compliance is expected to be greater with oral treatments than with SC infusion, RCTs have found no difference [19, 21]. In the absence of robust data indicating a difference between treatments, compliance was assumed to be comparable across all regimens

DFO desferrioxamine, DFP deferiprone, DFX deferasirox, LIC liver iron concentration, NYHA New York Heart Association, $R C T$ randomised controlled trial, $S C$ subcutaneous, $S F C$ serum ferritin concentration, $S P C$ summary of product characteristics

Lower and upper limits for sensitivity analysis were calculated from standard errors (SE); for treatment arms with zero events, the number of patients and events was increased by 0.5 to create a SE which could be used to estimate the upper limit. A summary of the values used in the model is given in Table 2 .

\subsubsection{Adverse Events}

Only AEs specifically mentioned as areas of concern within the summaries of product characteristics (SPCs) [12, 15, 17] that were also likely to impact upon healthcare costs and quality of life were included in the model. While DFX has been cited as a factor in a number of treatment-related deaths across several disease areas [48], no quantitative data were published on thalassaemia patients with transfusional iron overload, and so it was conservatively assumed that DFX was not associated with excess mortality.

DFP is associated with agranulocytosis and neutropenia events, with the SPC quoting rates of 0.6 and 2.5 per 100 patient-years, respectively. These were converted into annual rates of 0.6 and $2.5 \%$ [15], respectively, with an assumed agranulocytosis mortality rate of $13.83 \%$ [49]. The mortality rate for agranulocytosis is based on post-marketing reporting of 13 deaths from 94 cases. However, 11 of these deaths (from 45 cases) occurred prior to the implementation of a physician and patient education programme in 2007. Fewer deaths have occurred since this time ( 2 deaths from 49 cases), and the true mortality rate is likely to be less than that used in the model [49].
DFX is associated with hepatitis and Fanconi syndrome, with a hepatitis rate of $0.7 \%$ assumed based on the DFX prescribing information [50]. A specific rate for Fanconi syndrome is not reported in the DFX prescribing information; data from Yacobovich et al. [51] were therefore used. It was conservatively assumed that the four cases reported represented a minimum estimate of the rate for the entire transfusion-dependent thalassaemia population requiring iron chelation for that country (estimated at 500) [51]. This is consistent with the prescribing information for DFX, which lists Fanconi syndrome as an uncommon AE $(<1 \%)$ [50].

While DFO is associated with neutropenia, in the absence of published rates it was conservatively assumed that DFO was not associated with any AEs. Due to the lack of appropriate data on AEs with combination therapy, it was assumed that the rate of AEs was equivalent to DFP monotherapy. A summary of the values used in the model is given in Table 2 .

\subsubsection{Utility Data}

It was conservatively assumed that all patients with cardiac morbidity would have the mildest form (New York Heart Association [NYHA] class I). A utility score of 0.921 was calculated for this stage based on an average of utility values identified by searching the TUFTS cost-effectiveness analysis registry [52]. As the baseline utility for NYHA I is above the baseline values for chelation therapies, a proportional decrement was calculated and applied to the utility value for chelation $(7.9 \%$ decrement from 
Table 2 Values used in the model

\begin{tabular}{|c|c|c|c|}
\hline & Source data & Value used in the model & $\begin{array}{l}\text { Variation in sensitivity } \\
\text { analysis (upper, lower) }\end{array}$ \\
\hline \multicolumn{4}{|l|}{ Assumptions } \\
\hline Patient weight & $\begin{array}{l}\text { Average weight of men/women } \\
\text { from BNF [56] }\end{array}$ & $63 \mathrm{~kg}$ & $58.00,68.00^{\mathrm{a}}$ \\
\hline \multicolumn{4}{|l|}{ Efficacy } \\
\hline $\begin{array}{l}\text { Cardiac morbidity-DFP or } \\
\text { combination therapy }\end{array}$ & Non-RCT; $4 \%$ over 5 years [43] & $4 \%$ & $0.00,9.23^{\mathrm{b}}$ \\
\hline Cardiac morbidity_DFO/DFX & Non-RCT; $21 \%$ over 5 years [43] & $21 \%$ & $11.78,30.22^{\mathrm{b}}$ \\
\hline $\begin{array}{l}\text { Cardiac mortality-DFP/ } \\
\text { combination therapy }\end{array}$ & RCT: 0 deaths over 5 years [34] & $0 \%$ at 5 years & $0,2.49^{\mathrm{b}}$ \\
\hline Cardiac mortality—DFO/DFX & $\begin{array}{l}\text { RCT: } 4.8 \% \text { mortality over } \\
5 \text { years [34] }\end{array}$ & $4.8 \%$ at 5 years & $1.58,9.71^{\mathrm{b}}$ \\
\hline $\begin{array}{l}\text { Utility associated with cardiac } \\
\text { morbidity }\end{array}$ & $0.921[52]$ & $\begin{array}{l}7.9 \% \text { decrement applied to the utility } \\
\text { value for each treatment regimen }\end{array}$ & $0.815,1.000^{\mathrm{a}}$ \\
\hline \multicolumn{4}{|l|}{ Adverse events } \\
\hline $\begin{array}{l}\text { DFP/combination therapy- } \\
\text { agranulocytosis }\end{array}$ & $\begin{array}{l}\text { Product SPC: } 0.6 \text { per } 100 \text { patient- } \\
\text { years [15] }\end{array}$ & Annual rate of $0.6 \%$ & $0.21,0.35^{\mathrm{c}}$ \\
\hline $\begin{array}{l}\text { DFP/combination therapy- } \\
\text { neutropenia }\end{array}$ & $\begin{array}{l}\text { Product SPC: } 2.5 \text { per } 100 \text { patient- } \\
\text { years [15] }\end{array}$ & Annual rate of $2.5 \%$ & $1.88,3.13^{\mathrm{c}}$ \\
\hline DFX-hepatitis & Product SPC: $0.7 \%$ [17] & $0.7 \%$ & $0.02 \%, 1.58 \%^{\mathrm{b}}$ \\
\hline DFX_Fanconi syndrome & Clinical case reports: $0.8 \%$ [51] & $0.8 \%$ & $0.02 \%, 1.63 \%^{\mathrm{c}}$ \\
\hline DFO—no AEs & - & - & - \\
\hline $\begin{array}{l}\text { Risk of mortality associated } \\
\text { with agranulocytosis }\end{array}$ & Post-marketing data: $13.83 \%$ & $13.83 \%$ & $6.85,20.81^{\mathrm{b}}$ \\
\hline \multicolumn{4}{|l|}{ Utility associated with AEs } \\
\hline Agranulocytosis & Published model: 0.460 [54] & $\begin{array}{l}0.460 \text { for } 7 \text { days, } 54.0 \% \text { decrement } \\
\text { from perfect health }\end{array}$ & $0.345,0.575^{\mathrm{c}}$ \\
\hline Neutropenia & Published model: 0.782 [55] & $\begin{array}{l}0.782 \text { for } 1 \text { day, } 21.8 \% \text { decrement } \\
\text { from perfect health }\end{array}$ & $0.587,0.978^{\mathrm{c}}$ \\
\hline Hepatitis & Published model: 0.770 [53] & $\begin{array}{l}0.770 \text { for } 365 \text { days, } 23.0 \% \text { decrement } \\
\text { from perfect health }\end{array}$ & $0.710,0.810^{\mathrm{c}}$ \\
\hline Fanconi syndrome & No data available & No impact on QoL & No variation \\
\hline \multicolumn{4}{|l|}{ Route of administration utility } \\
\hline Oral & $\begin{array}{l}\text { Prior economic evaluation: } \\
0.840[28]\end{array}$ & 0.840 & $0.66,1.00^{\mathrm{d}}$ \\
\hline SC infusion & $\begin{array}{l}\text { Prior economic evaluation: } \\
0.660[28]\end{array}$ & $\begin{array}{l}0.66 \text { for five times weekly DFO } \\
0.696 \text { for four times weekly combination } \\
\text { therapy }\end{array}$ & $0.25^{\mathrm{b}}, 0.84^{\mathrm{d}}$ \\
\hline
\end{tabular}

$A E$ adverse event, $B N F$ British National Formulary, $D F O$ desferrioxamine, $D F P$ deferiprone, $D F X$ deferasirox, $Q o L$ quality of life, $R C T$ randomized controlled trial, $S C$ subcutaneous, $S P C$ summary of product characteristics

${ }^{\mathrm{a}}$ Reported in source. ${ }^{\mathrm{b}}$ Calculated based on standard error reported in source. ${ }^{\mathrm{c}}$ Calculated by varying the reported value $\pm 25 \%$. ${ }^{\mathrm{d}}$ Calculated value would be outside the plausible range, value set to plausible maximum (i.e., maximum SC infusion utility cannot be higher than the standard oral utility, and the minimum oral utility cannot be lower than the standard SC infusion utility)

perfect health). A summary of the values used in the model is given in Table 2.

Utility scores for each $\mathrm{AE}$ were obtained from the published literature [53-55], with the duration for which the decrement was applied based on the expert opinion of two consultant haematologists and one consultant nephrologist. As no published utility scores for Fanconi syndrome exist, it was conservatively assumed that the condition has no impact on quality of life. The utility values, event duration and decrement from perfect health used in the model are given in Table 2.

The effect of the administration of iron chelation therapy on quality of life has been examined by Karnon et al. [28] using a time-trade-off method. This study estimated a 
utility score of 0.660 for SC DFO (administered five times weekly) and 0.840 for oral DFX. When used in combination therapy, DFO was assumed to be administered four times weekly; the utility for combination therapy was therefore the utility for DFX minus $80 \%$ of the difference between DFX and combination therapy $(0.84-((0.84-0.66)$ $\times 0.8)=0.696)$. As no studies have assessed the comparative utility scores of DFP and DFX, these treatments were assumed to have the same utility score, as both are administered orally. A summary of the values used in the model is given in Table 2. AE and cardiac morbidity utilities were applied as a proportional decrement of the utility associated with the administration route for each treatment regimen, i.e. the utility for a patient receiving DFX who developed hepatitis was $0.840-(0.23 \times 0.840)$, rather than $0.840-$ 0.230 .

\subsubsection{Cost Data}

It was conservatively assumed that all patients with cardiac morbidity would have the mildest form (NYHA I) and would incur no costs as a consequence of this.

Drug acquisition costs for the latest year available for each treatment (2010/2011) were obtained from the British National Formulary [56]. The model assumes a crude average price per mg across all dosages and formulations, with the cost of DFO based on the generic drug in the base case. Treatment costs per day and per year are presented in Table 3, using an average male/female weight of $63 \mathrm{~kg}$ [56] and a daily dose representing the mid-point from each product SPC in the base case. This weight is consistent with the average patient weight from US DFP patient registries of $62 \mathrm{~kg}$ [57]. These values were varied in sensitivity analysis within the dose ranges recommended in the respective UK SPCs.
As DFP and DFX are given orally, administration costs were applied to DFO only; these are summarized in Table 4 for the base case where all patients are assumed to use a balloon infuser. In Scenario 4, where DFO patients are assumed to use a pump instead of balloon infuser, one pump (£857.97) and 2.91 batteries (£306.66 each) replaced the balloon infusers. Total administration costs for DFO and combination therapy were therefore $£ 2,441$ and $£ 1,953$, respectively. All administration cost data are based on a previous economic evaluation by Karnon et al. [28], inflated from 2005 to $2010 / 2011$ prices using standard inflation indices [58].

The monitoring tests required and frequency of testing were applied according to the product SPCs and UK Thalassaemia Society guidelines (Table 5) [5]. For combination therapy, the rates for DFP testing have been combined with those for DFO to provide a conservative estimate. There is currently no national set NHS price list for laboratory tests; all costs were therefore based on internal costing exercises provided by the Quality Manager at the Department of Laboratory Haematology at the John Radcliffe Hospital, Oxford, unless specified (personal communication).

The costs for managing treatment-related adverse events were obtained from national sources $[56,59]$ and validated by the expert opinion of two consultant haematologists and one consultant nephrologist, except for hepatitis, where a previous UK economic evaluation was used [60]. Estimated costs were: $£ 3,782$ for agranulocytosis (Healthcare Resource Group [HRG] code PA48a) [59]; £684 for neutropenia (HRG code PA48a) [59]; £163 for Fanconi syndrome (30 days of treatment with sodium bicarbonate capsules and phosphate tablets and one nephrologist consultation, using the mid-point of reported resolution times [51, 61-64]) [56, 59]; and $£ 411$ for hepatitis (3.3 consultant

Table 3 Treatment costs

\begin{tabular}{|c|c|c|c|c|c|c|}
\hline & Average cost/mg $(\mathfrak{l})$ & Daily dose $(\mathrm{mg} / \mathrm{kg})^{\mathrm{a}}$ & mg/Day & Cost/day (£) & Days of Tx/week (days of Tx/year) ${ }^{b}$ & Cost/year $(\mathfrak{f})$ \\
\hline \multicolumn{7}{|l|}{ DFP } \\
\hline Ferriprox ${ }^{\circledR}$ & 0.0032 & 75.0 & 4,725 & 15.12 & $7(365)$ & 5,519 \\
\hline \multicolumn{7}{|l|}{ DFX } \\
\hline Exjade $^{\circledR}$ & 0.0336 & 30.0 & 1,890 & 63.50 & $7(365)$ & 23,179 \\
\hline \multicolumn{7}{|l|}{ DFO } \\
\hline Generic DFO & 0.0085 & 40.0 & 2,520 & 21.48 & $5(260)$ & 5,584 \\
\hline \multicolumn{7}{|c|}{ Combination therapy } \\
\hline Ferriprox ${ }^{\circledR}$ & 0.0032 & 75.0 & 4,725 & 15.12 & $7(365)$ & 5,519 \\
\hline Generic DFO & 0.0085 & 40.0 & 2,520 & 21.48 & $4(208)$ & 4,467 \\
\hline Total cost & & - & - & - & - & 9,986 \\
\hline
\end{tabular}

$D F O$ desferrioxamine, $D F P$ deferiprone, $D F X$ deferasirox, $T x$ treatment

${ }^{a}$ Varied in sensitivity analysis around the upper and lower values reported in the source. ${ }^{\text {b }}$ Varied in sensitivity analysis by $\pm 25 \%$, or set to the maximum value where variation exceeded the maximum 
Table 4 Administration costs for DFO

\begin{tabular}{lrlll}
\hline & $\begin{array}{l}\text { Unit } \\
\text { cost }(\mathfrak{f})\end{array}$ & $\begin{array}{l}\text { Patients } \\
(\%)\end{array}$ & $\begin{array}{l}\text { Number/ } \\
\text { patient }\end{array}$ & $\begin{array}{l}\text { Annual cost/ } \\
\text { patient }(\mathfrak{f})\end{array}$ \\
\hline Balloon infuser & 34.61 & 100 & 260 & 8,999 \\
Portacath & 288.69 & 5 & 0.5 & 7 \\
Needles for portacath & 4.59 & 5 & 300 & 69 \\
Portacath surgery & $1,128.03$ & 5 & 0.5 & 28 \\
Syringes & 0.13 & 100 & 55.4 & 7 \\
Needles & 0.06 & 100 & $300^{\mathrm{a}}$ & 17 \\
Infusion sets & 1.30 & 100 & $171.2^{\mathrm{a}}$ & 222 \\
Tape & 0.74 & 100 & 10 & 7 \\
Alcohol pads & 0.04 & 100 & $310.9^{\mathrm{b}}$ & 14 \\
Gauze & 0.03 & 100 & 300 & 10 \\
Sharps bins & 1.49 & 100 & 2 & 3 \\
Home delivery costs & 306.66 & 100 & 1 & 307 \\
Total cost & & & & $9,690^{\mathrm{c}}$ \\
\hline
\end{tabular}

All values were varied $\pm 25 \%$ in sensitivity analysis using a gamma distribution, with the exception of those marked ${ }^{\mathrm{a}}$ or ${ }^{\mathrm{b}}$. Where this variation exceeded the maximum plausible value, the maximum/ minimum limit was used. ${ }^{\text {a } V a l u e ~ w a s ~ v a r i e d ~ i n ~ s e n s i t i v i t y ~ a n a l y s i s ~}$ based on data reported in the source $(0.00,253.95)$. ${ }^{\mathrm{b}}$ Value was varied in sensitivity analysis based on data reported in the source $(0.00$, $369.75)$. ${ }^{\mathrm{c}}$ The cost applied to combination therapy was adjusted to $80 \%$ of this value as DFO was assumed to be given four times weekly

appointments per year) [60]. These values were varied $\pm 25 \%$ in sensitivity analysis.

\subsubsection{Sensitivity Analysis}

Uncertainty surrounding the model inputs was assessed through sensitivity analysis. One-way analyses were performed using realistic minimum and maximum individual model inputs and a tornado diagram was generated to assess the main drivers of cost effectiveness. The effect of different dosing regimens was assessed in a two-way sensitivity analysis. In addition, all parameters were simultaneously varied in a probabilistic sensitivity analysis. Costs, patient weights, and doses were assumed to follow gamma distributions, while utilities and probabilities were assigned beta distributions, in line with best practice [65, 66]. All model inputs, with the exception of drugs with fixed prices, were varied in sensitivity analysis.

\section{Results: Economic Model}

\subsection{Base Case}

The costs and QALYs associated with the different iron chelation regimens per patient over a 5-year period are presented in Table 6. DFP has the lowest overall cost of all the treatment options and the highest QALY gain, and is therefore the dominant treatment strategy. DFX produced a higher QALY gain than both combination therapy and DFO, but at a greater total cost, giving incremental costeffectiveness ratios (ICERs) of $£ 36,141$ and $£ 42,923$, respectively. The ICER for combination therapy compared with DFO was $£ 59,093$.

\subsection{Scenario 1-Cardiac Mortality Only}

This scenario conservatively assumed that there is no difference in cardiac morbidity between treatments and considers only the impact of cardiac mortality. DFP again resulted in greater QALY gains and cost savings than all other treatments (Table 6), and is therefore the dominant strategy in this scenario. The ICERs for DFX versus combination therapy and DFO were $£ 34,817$ and $£ 42,635$, respectively, while the ICER for combination therapy versus DFO was $£ 63,394$.

\subsection{Scenario 2-Cardiac Morbidity Only}

This scenario assumed that there is no difference between treatments for cardiac mortality and only considers cardiac morbidity. DFP was again the dominant strategy, resulting in greater QALY gains and cost savings than all other treatments (Table 6). The ICERs for DFX versus combination therapy and DFO were $£ 35,229$ and $£ 42,923$, respectively, while the ICER for combination therapy versus DFO was $£ 70,174$.

\subsection{Scenario 3-1-Year Model}

This scenario conservatively assumed that there is no difference between treatments with respect to cardiac morbidity or mortality. A 1-year time horizon was used; costs were therefore not discounted in this scenario. DFP was the dominant treatment strategy, resulting in greater QALY gains (although this was marginal) and cost savings than all other treatments (Table 7). The ICERs for DFX versus combination therapy and DFO were $£ 34,161$ and $£ 42,701$, respectively, while the ICER for combination therapy versus DFO was $£ 76,605$.

\subsection{Scenario 4-DFO Administered by Battery- Operated Pump}

This scenario assumed that all DFO patients received treatment via a pump instead of a balloon infuser. DFP was the dominant treatment, resulting in greater QALY gains and cost savings than all other treatments (Table 7). The ICERs for DFX versus combination therapy and DFO were 
Table 5 Monitoring costs

$D F O$ desferrioxamine, $D F P$ deferiprone, $D F X$ deferasirox, $S A$ sensitivity analysis

${ }^{a}$ All test frequencies were varied around the maximum and minimum values reported in the source data. ${ }^{\mathrm{b}}$ All costs based on personal communication, except audiometry (National Tariff for Adult Hearing Services [69]) and ophthalmology (National Tariff for Ophthalmology outpatient appointment; consultant-led follow up attendance, single professional contact, treatment function 130 [69]). ${ }^{c}$ Varied $\pm 25 \%$ in sensitivity analysis. ${ }^{\mathrm{d}}$ Varied in sensitivity analysis based on values reported in an alternative source [70]. ${ }^{\mathrm{e}}$ The summary of product characteristics for DFP states that monitoring should be performed 4-6 times per year [15]; in this analysis it was conservatively assumed that monitoring occurred monthly

\begin{tabular}{|c|c|c|c|c|}
\hline Test & $\begin{array}{l}\text { Frequency/ } \\
\text { year }^{\mathrm{a}}\end{array}$ & $\begin{array}{l}\text { Cost/ } \\
\text { test }^{b}(£)\end{array}$ & $\begin{array}{l}\text { Variation of cost in SA } \\
\text { (upper, lower) ( }(\mathfrak{)})\end{array}$ & Total cost/year $(£)$ \\
\hline \multicolumn{5}{|l|}{ DFP } \\
\hline Neutrophil count & 52.00 & 3.47 & $2.61^{\mathrm{c}}, 15.50^{\mathrm{d}}$ & 180.68 \\
\hline Serum zinc & 4.00 & 10.28 & $7.71^{\mathrm{c}}, 38.75^{\mathrm{d}}$ & 41.12 \\
\hline Ferritin $^{\mathrm{e}}$ & 12.00 & 3.47 & $2.61^{\mathrm{c}}, 44.10^{\mathrm{d}}$ & 41.17 \\
\hline Total monitoring cost/year & & & & 263.50 \\
\hline \multicolumn{5}{|l|}{ DFX } \\
\hline Serum creatinine (year 1) & 15.00 & 1.51 & $1.13^{\mathrm{c}}, 14.30^{\mathrm{d}}$ & 22.67 \\
\hline $\begin{array}{l}\text { Serum creatinine } \\
\text { (subsequent years) }\end{array}$ & 12.00 & 1.51 & $1.13^{\mathrm{c}}, 14.30^{\mathrm{d}}$ & 18.13 \\
\hline Liver function (year 1) & 15.00 & 1.60 & $1.20^{\mathrm{c}}, 17.88^{\mathrm{d}}$ & 24.06 \\
\hline $\begin{array}{l}\text { Liver function (subsequent } \\
\text { years) }\end{array}$ & 12.00 & 1.60 & $1.20^{\mathrm{c}}, 17.88^{\mathrm{d}}$ & 19.24 \\
\hline Urinalysis (year 1) & 15.00 & 1.94 & $1.46^{\mathrm{c}}, 2.43^{\mathrm{c}}$ & 29.14 \\
\hline Urinalysis (subsequent years) & 12.00 & 1.94 & $1.46^{\mathrm{c}}, 2.43^{\mathrm{c}}$ & 23.32 \\
\hline Audiometry & 1.00 & 61.00 & $45.75^{\mathrm{c}}, 76.25^{\mathrm{c}}$ & 61.00 \\
\hline Ophthalmology & 1.00 & 67.00 & $50.25^{\mathrm{c}}, 73.75^{\mathrm{c}}$ & 67.00 \\
\hline Ferritin & 12.00 & 3.47 & $2.61^{\mathrm{c}}, 44.10^{\mathrm{d}}$ & 41.70 \\
\hline Total monitoring cost/year & & & & $\begin{array}{l}245.56 / 230.39 \\
\quad \text { (year 1/subsequent } \\
\text { years) }\end{array}$ \\
\hline \multicolumn{5}{|l|}{ DFO } \\
\hline Audiometry & 4.00 & 61.00 & $45.75^{\mathrm{c}}, 76.25^{\mathrm{c}}$ & 244.00 \\
\hline Ophthalmology & 4.00 & 67.00 & $50.25^{\mathrm{c}}, 73.75^{\mathrm{c}}$ & 268.00 \\
\hline Ferritin & 4.00 & 3.47 & $2.61^{\mathrm{c}}, 44.10^{\mathrm{d}}$ & 13.90 \\
\hline Total monitoring cost/year & & & & 525.90 \\
\hline \multicolumn{5}{|l|}{ DFO-DFP combination } \\
\hline Neutrophil count & 52.00 & 3.47 & $2.61^{\mathrm{c}}, 15.50^{\mathrm{d}}$ & 180.68 \\
\hline Serum zinc & 4.00 & 10.28 & $7.71^{\mathrm{c}}, 38.75^{\mathrm{d}}$ & 41.12 \\
\hline Ferritin & 12.00 & 3.47 & $2.61^{\mathrm{c}}, 44.10^{\mathrm{d}}$ & 41.70 \\
\hline Audiometry & 4.00 & 61.00 & $45.75^{\mathrm{c}}, 76.25^{\mathrm{c}}$ & 244.00 \\
\hline Ophthalmology & 4.00 & 67.00 & $50.25^{\mathrm{c}}, 73.75^{\mathrm{c}}$ & 268.00 \\
\hline Total monitoring cost/year & & & & 775.50 \\
\hline
\end{tabular}

$£ 83,385$ and $£ 83,770$, respectively, while the ICER for combination therapy versus DFO was $£ 84,687$.

\subsection{Sensitivity Analysis}

\subsubsection{One-Way Sensitivity Analysis}

The results of the sensitivity analysis, comparing DFP with each of the other treatment options, are represented in tornado diagrams in Fig. 2, where the vertical line represents the base-case ICER. A negative figure on the x-axis (i.e. $<£ 0$ ) indicates that DFP is the dominant treatment strategy. For DFP versus DFX, no parameter variations resulted in an ICER $\geq £ 0$, indicating that DFP was the dominant strategy in all plausible scenarios. For DFP versus DFO or combination therapy, the main drivers of cost effectiveness were the utility values associated with the route of administration. DFP always remained the dominant strategy when varying these utilities; while the ICER tends to infinity when the utility of administration is equal, DFP remains the least expensive treatment option.

\subsubsection{Two-Way Sensitivity Analysis}

Two-way sensitivity analyses were performed to assess the impact of varying the administered dose of DFP compared with the other treatment options. DFP remained the dominant treatment strategy irrespective of the dose comparison.

\subsubsection{Probabilistic Sensitivity Analysis}

This analysis was performed to account for parameter uncertainty. Cost-effectiveness planes for DFP versus the 
Table 6 Base-case analysis

\begin{tabular}{|c|c|c|c|c|c|c|c|c|c|}
\hline \multicolumn{5}{|c|}{ Discounted value $^{\mathrm{a}}$ (undiscounted value) } & \multicolumn{2}{|c|}{ Base-case analysis } & \multicolumn{3}{|c|}{ Incremental analysis } \\
\hline & $\begin{array}{l}\text { Drug costs } \\
(£)\end{array}$ & $\begin{array}{l}\text { Admin costs } \\
(£)\end{array}$ & $\begin{array}{l}\text { Monitoring costs } \\
\text { (£) }\end{array}$ & $\begin{array}{l}\text { AE costs } \\
(£)\end{array}$ & $\begin{array}{l}\text { Total costs } \\
\text { (£) }\end{array}$ & QALYs & $\begin{array}{l}\text { Inc. costs } \\
(£)\end{array}$ & $\begin{array}{l}\text { Inc. } \\
\text { QALYs }\end{array}$ & $\operatorname{ICER}(£)$ \\
\hline $\begin{array}{l}\text { DFP } \\
\quad\left(\text { Ferriprox }{ }^{\circledR}\right)\end{array}$ & $\begin{array}{l}25,775 \\
(27,577)\end{array}$ & $\begin{array}{l}0 \\
(0)\end{array}$ & $\begin{array}{l}1,231 \\
(1,317)\end{array}$ & $\begin{array}{l}186 \\
(199)\end{array}$ & $\begin{array}{l}27,191 \\
(29,093)\end{array}$ & $\begin{array}{l}3.918 \\
(4.192)\end{array}$ & & & \\
\hline DFO (Generic) & $\begin{array}{l}25,602 \\
(27,374)\end{array}$ & $\begin{array}{l}44,429 \\
(47,505)\end{array}$ & $\begin{array}{l}2,411 \\
(2,578)\end{array}$ & $\begin{array}{l}0 \\
(0)\end{array}$ & $\begin{array}{l}72,442 \\
(77,457)\end{array}$ & $\begin{array}{l}3.006 \\
(3.213)\end{array}$ & $\begin{array}{l}45,251 \\
(48,364)\end{array}$ & $\begin{array}{l}-0.912 \\
(-0.979)\end{array}$ & $\begin{array}{l}\text { Dominated } \\
\text { Dominated }\end{array}$ \\
\hline $\begin{array}{l}\text { Combination } \\
\text { therapy }\end{array}$ & $\begin{array}{l}46,636 \\
(49,898)\end{array}$ & $\begin{array}{l}36,203 \\
(38,736)\end{array}$ & $\begin{array}{l}3,622 \\
(3,875)\end{array}$ & $\begin{array}{l}186 \\
(199)\end{array}$ & $\begin{array}{l}86,647 \\
(92,708)\end{array}$ & $\begin{array}{l}3.246 \\
(3.473)\end{array}$ & $\begin{array}{l}14,205 \\
(15,251)\end{array}$ & $\begin{array}{l}0.240 \\
(0.260)\end{array}$ & $\begin{array}{l}59,093 \\
(58,664)\end{array}$ \\
\hline DFX $\left(\right.$ Exjade $\left.^{\circledR}\right)$ & $\begin{array}{l}106,272 \\
(113,629)\end{array}$ & $\begin{array}{l}0 \\
(0)\end{array}$ & $\begin{array}{l}1,071 \\
(1,145)\end{array}$ & $\begin{array}{l}19 \\
(20)\end{array}$ & $\begin{array}{l}107,363 \\
(114,795)\end{array}$ & $\begin{array}{l}3.819 \\
(4.083)\end{array}$ & $\begin{array}{l}20,716 \\
(22,087)\end{array}$ & $\begin{array}{l}0.573 \\
(0.610)\end{array}$ & $\begin{array}{l}36,141 \\
(36,224)\end{array}$ \\
\hline
\end{tabular}

${ }^{a}$ Costs and QALYs are discounted at a rate of $3.5 \%$, in line with UK Treasury guidelines

$A E$ adverse events, $D F O$ desferrioxamine, $D F P$ deferiprone, $D F X$ deferasirox, ICER incremental cost-effectiveness ratio, Inc. incremental, $Q A L Y$ quality-adjusted life year

Table 7 Scenario $1-4$

\begin{tabular}{|c|c|c|c|c|c|c|c|c|}
\hline & \multicolumn{8}{|c|}{ Discounted value $^{\mathrm{a}}$ (undiscounted value) } \\
\hline & \multicolumn{2}{|l|}{ Scenario 1} & \multicolumn{2}{|l|}{ Scenario 2} & \multicolumn{2}{|l|}{ Scenario $3^{\mathrm{b}}$} & \multicolumn{2}{|l|}{ Scenario 4} \\
\hline & Total costs $(\mathfrak{f})$ & QALYs & Total costs $(\mathfrak{f})$ & QALYs & Total costs $(£)$ & QALYs & Total costs $(£)$ & QALYs \\
\hline DFP $\left(\right.$ Ferriprox ${ }^{\circledR}$ ) & $\begin{array}{l}27,191 \\
(29,093)\end{array}$ & $\begin{array}{l}3.923 \\
(4.197)\end{array}$ & $\begin{array}{l}27,191 \\
(29,093)\end{array}$ & $\begin{array}{l}3.918 \\
(4.192)\end{array}$ & 5,822 & 0.840 & $\begin{array}{l}27,191 \\
(29,093)\end{array}$ & $\begin{array}{l}3.918 \\
(4.192)\end{array}$ \\
\hline DFO (Generic) & $\begin{array}{l}72,422 \\
(77,457)\end{array}$ & $\begin{array}{l}3.026 \\
(3.235)\end{array}$ & $\begin{array}{l}73,836 \\
(79,001)\end{array}$ & $\begin{array}{l}3.064 \\
(3.277)\end{array}$ & 15,800 & 0.660 & $\begin{array}{l}39,210 \\
(41,924)\end{array}$ & $\begin{array}{l}3.006 \\
(3.213)\end{array}$ \\
\hline Combination therapy & $\begin{array}{l}86,647 \\
(92,708)\end{array}$ & $\begin{array}{l}3.250 \\
(3.477)\end{array}$ & $\begin{array}{l}86,647 \\
(92,708)\end{array}$ & $\begin{array}{l}3.246 \\
(3.473)\end{array}$ & 18,554 & 0.696 & $\begin{array}{l}59,568 \\
(63,734)\end{array}$ & $\begin{array}{l}3.246 \\
(3.473)\end{array}$ \\
\hline DFX $\left(\right.$ Exjade $\left.^{\circledR}\right)$ & $\begin{array}{l}107,363 \\
(114,795)\end{array}$ & $\begin{array}{l}3.845 \\
(4.111)\end{array}$ & $\begin{array}{l}109,428 \\
(117,083)\end{array}$ & $\begin{array}{l}3.893 \\
(4.164)\end{array}$ & 23,429 & 0.839 & $\begin{array}{l}107,363 \\
(114,795)\end{array}$ & $\begin{array}{l}3.819 \\
(4.083)\end{array}$ \\
\hline
\end{tabular}

${ }^{a}$ Costs and QALYs are discounted at a rate of $3.5 \%$, in line with UK Treasury guidelines [46]. ${ }^{b}$ No discounting was applied in Scenario 3 as a 1-year horizon was used

$D F O$ desferrioxamine, $D F P$ deferiprone, $D F X$ deferasirox, $Q A L Y$ quality-adjusted life year

other comparators, plotting the incremental costs and QALYs for DFP versus each chelator in the base-case scenario, are shown in Fig. 3. DFP was the most costeffective treatment option in all scenarios. The likelihood of DFP being cost effective at a willingness-to-pay threshold of $£ 20,000$ per QALY was: base case, $99.86 \%$; scenario 1, $99.86 \%$; scenario 2, $99.84 \%$; scenario 3, $99.82 \%$; scenario 4, $99.34 \%$.

\section{Discussion}

A de novo health economic model was developed to assess the cost effectiveness of DFP monotherapy compared with DFX and DFO monotherapy or DFO-DFP combination therapy. Published RCT evidence suggests that all chelators have a similar, or minimally different, effect on LIC and
SFC levels [18, 19, 31]. DFP has been shown to be more effective for reduction of excess cardiac iron and in reducing cardiac mortality and morbidity compared with DFO monotherapy, as reported in the SPC for DFP [15]. Combination therapy has also been shown to be more effective than DFO monotherapy in reducing SFC, LIC and cardiac iron levels [24, 25]. However, the correlation between a reduction in SFC or LIC and cardiac morbidity and/or mortality is weak, with only cardiac iron levels shown to have a high predictive value [22]. Therefore, only reductions in cardiac iron levels were considered to have an impact on cardiac mortality and morbidity; reductions in SFC and LIC were assumed to have no effect on these outcomes.

The magnitude of cardiac iron reduction was comparable in separate RCTs by the same lead investigator for DFP versus DFO and combination therapy versus DFO [19, 25]. Equivalent efficacy regarding LIC and SFC was therefore 
Fig. 2 Tornado diagrams for the sensitivity analyses of DFP vs a DFX, b DFO, and c combination therapy. $B I$ balloon infuser, $D F O$ desferrioxamine, $D F P$ deferiprone, $D F X$ deferasirox, NYHA New York Heart Association, $T x$ treatment

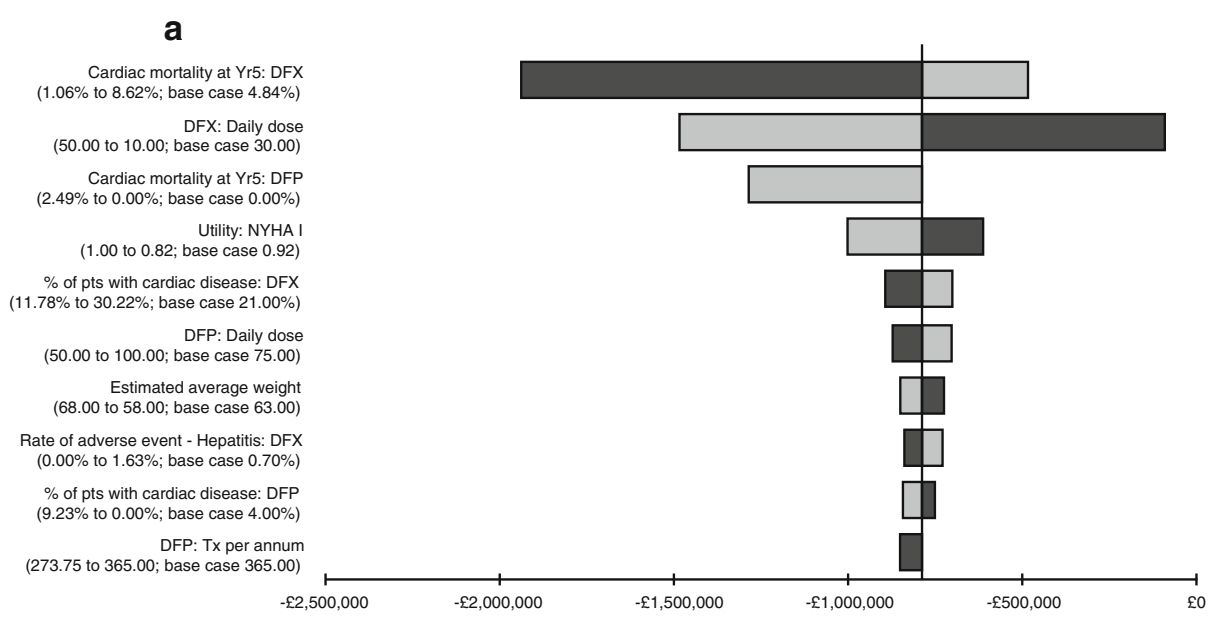

b

Utility: Route of administration - Ora (1.00 to 0.51; base case 0.84 ) Utility: Route of administration - Infusion (0.25 to 1.00 ; base case 0.66 ) Generic DFO: Daily dose
$(50.00$ to 20.00; base case 40.00 ) DFP: Daily dose
(50.00 to 100.00 ; base case 75.00 ) $\%$ of pts: Balloon infuser - $100 \% \mathrm{BI}$ (100.00\% to $75.00 \%$; base case $100.00 \%$ ) Cardiac mortality at Yr5: DFO (1.06\% to $8.62 \%$; base case $4.84 \%)$ DFP: Tx per annum Monitoring costs: Neutrophil count (£2.61 to £15.50; base case £3.47) Cardiac mortality at Yr5: DFP (2.49\% to $0.00 \%$; base case $0.00 \%)$ Utility: NYHA I
(1.00 to 0.82 ; base case 0.92$)$ (1.00 to 0.82 ; base case 0.92 ) $\stackrel{\longmapsto}{\longmapsto}$

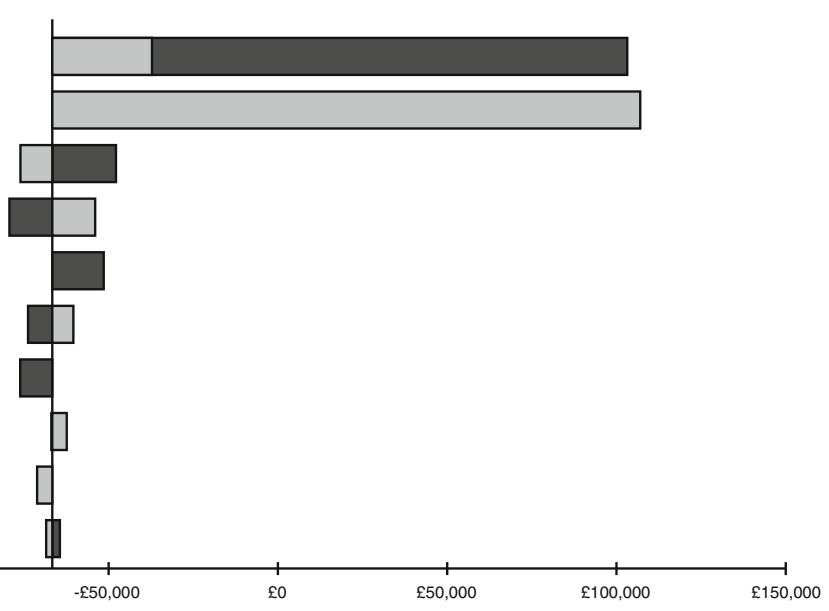

C

Utility: Route of administration - Oral (1.00 to 0.51; base case 0.84 ) Utility: Route of administration - Infusion
$(0.25$ to 1.00 ; base case 0.66$)$ DFP: Daily dose (50.00 to 100.00; base case 75.00 ) Unit cost: Balloon infuser
(£43 to £26; base case £35) Cardiac mortality at Yr5: DFP \& DFO combination $(0.00 \%$ to $7.39 \%$; base case $0.00 \%)$ DFP: Tx per annum DFP: Tx per annum
(273.75 to 365.00; base case 365.00) Combo: DFP - Tx per annum Cardiac mortality at Yr5: DFP Cardiac mortality at Yr5: DFP
$(2.49 \%$ to $0.00 \%$; base case $0.00 \%)$ Estimated average weight
00 to 58.00 ; base case 63.00 ) Combo: Generic DFO - Tx per annum (156.00 to 365.00; base case 208.00)

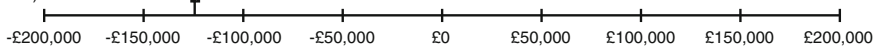

assumed in the model for DFO, DFX, DFP and combination therapy, with a cardiac benefit assumed for DFPcontaining regimens over DFO and DFX. Dosing assumptions were daily administration for DFP and DFX, while DFO was administered five times weekly, or four times weekly when given in combination with daily DFP.
In order to obtain a realistic view of the cost effectiveness of the agents of interest, the model also included AEs. Common AEs indicated in product SPCs which were likely to have an impact on patient quality of life and/or cost implications were included. The AE assessment was limited by the availability and quality of reporting of AEs 


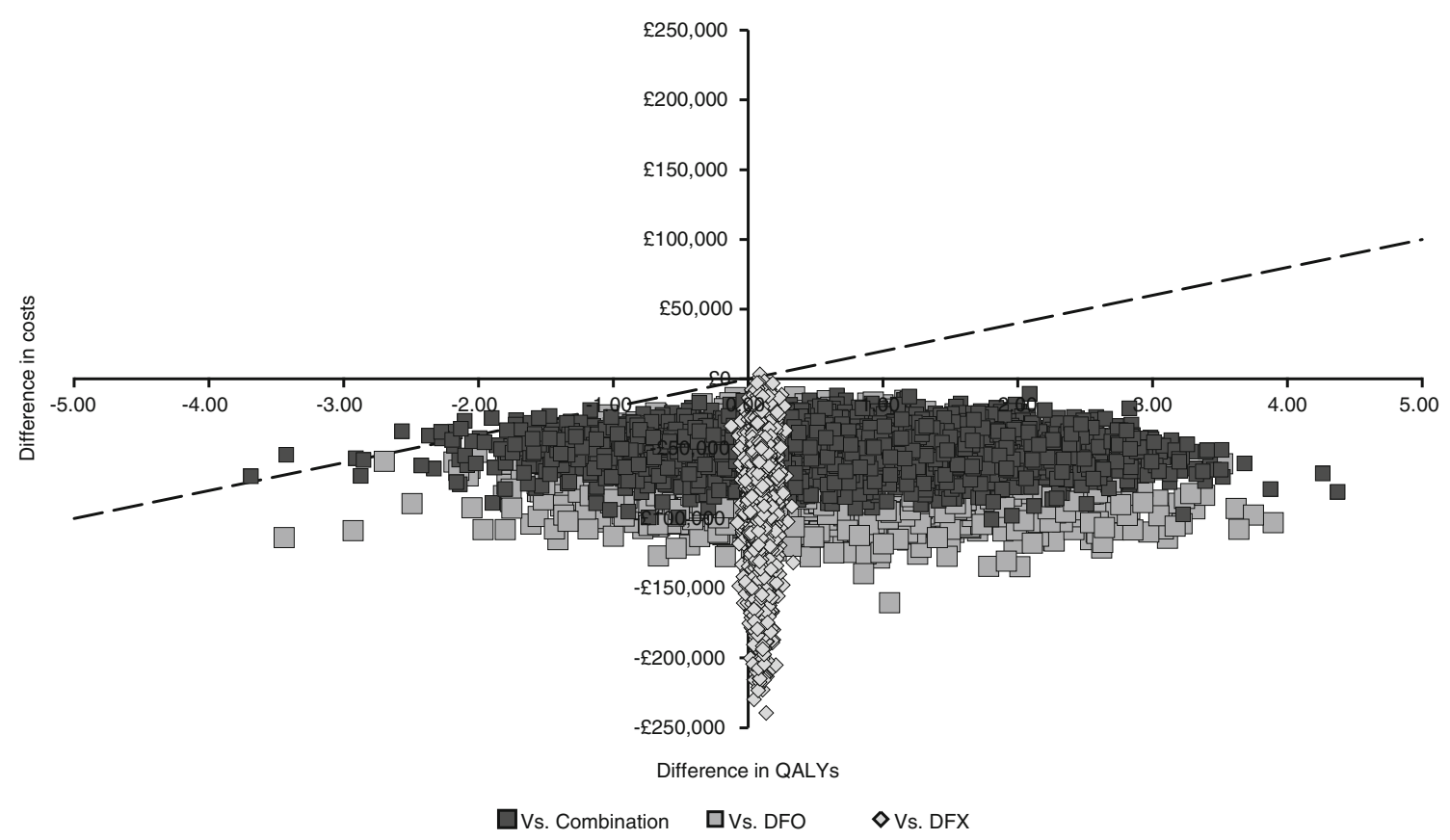

Fig. 3 Cost-effectiveness plane-incremental costs and effects for DFP vs comparators. Each point represents a simulation, while the dotted line represents the cost-effectiveness threshold (£20,000/

within the clinical studies, which were varied in sensitivity analysis to assess the impact of uncertainty.

The model base-case results suggest that DFP monotherapy is the dominant strategy (more effective and less costly), compared with DFX and DFO monotherapy or combination therapy. DFP is associated with 5 -year cost savings of $£ 80,172$ per patient relative to DFX, $£ 45,251$ per patient relative to DFO and $£ 59,456$ per patient relative to combination therapy. DFX was not cost effective relative to DFO combination therapy or monotherapy ( $£ 36,141$ / QALY and £59,093/QALY, respectively). Although combination therapy was less costly than DFX, it had a lower QALY gain due to the lower utility score associated with SC administration of DFO, placing combination therapy in the south-west quadrant of the cost-effectiveness plane. However, it should be considered that oral DFX has no proven cardiac morbidity or survival benefit over other treatment regimens, while combination therapy has been demonstrated to have benefits in terms of both cardiac morbidity and survival [42]. DFP monotherapy remained dominant in all scenarios, including a scenario where the cardiac benefits of the drug were excluded and all iron chelators were assumed to have the same efficacy. In this case, the time horizon was assumed to be 1 year, with DFP treatment resulting in a cost saving of $£ 17,607$ per patient relative to DFX.

The model used in this analysis is conservative in many of its assumptions, including $\mathrm{AE}$ rates for comparators, costs of $\mathrm{AE}$ rates, grade of cardiac disease applied to
QALY); combination is DFO-DFP. $D F O$ desferrioxamine, DFP deferiprone, $D F X$ deferasirox, $Q A L Y$ quality-adjusted life year

patients developing cardiac disease, and the compliance rate (which was assumed to be equal across all therapies). The majority of these assumptions bias the results against DFP. For example, we have conservatively assumed that DFX-induced Fanconi syndrome is not associated with a decrement in quality of life, and that only one outpatient nephrology appointment would be associated with its management. Furthermore, we have not considered the possibility that patients treated with DFX would develop either acute or chronic renal failure. However, the DFX SPC states that some patients within post-marketing studies developed renal failure requiring temporary or permanent renal dialysis [17]. Given that renal failure has a significant impact on patient quality of life, and that the annual cost of renal dialysis is likely to exceed $£ 8,000$ (based on the average cost of haemodialysis from NHS reference costs) [59], our model likely underestimates the true costs associated with DFX therapy.

As with any economic evaluation, the current model has limitations. It was necessary to make assumptions around efficacy based on a systematic review of the literature; such a review can only include data up to a specified time (in this case, 9 February 2011). It will therefore be necessary to re-evaluate the findings from this study as the evidence evolves. No full published studies reporting the long-term cardiac effects of DFX were identified by the systematic review; it was therefore necessary to use proxy data in order to develop assumptions surrounding this outcome. Equivalence was assumed for DFX and DFO regarding 
long-term cardiac effects based on RCT data which indicate that DFX is non-inferior to DFO in reducing cardiac iron, as measured by $\mathrm{T} 2 *$, with neither agent able to improve cardiac function as assessed by LVEF [67]. This assumption is further supported via non-RCT studies by Pepe et al. [21] and Berdoukas et al. [20] that demonstrate equivalent cardiac MRI T2* values between DFX and DFO. Another possible limitation is the assumption of equivalent efficacy regarding SFC and LIC for the three iron chelators. No RCT studies exist which directly compare DFP and DFX; it was therefore necessary to infer similar efficacy via comparison with DFO, which was found to have a similar effect on SFC and LIC when compared with DFP or DFX [18, 19, 31]. It should be noted that, while both studies comparing DFP and DFO found no significant difference in SFC or LIC between the treatments [18, 19], Pennell et al. [19] observed a non-significant trend towards greater reduction of these assessments with DFO. However, these potential differences in effect on SFC and LIC between treatment regimens, even if they had been statistically significant, were small and are unlikely to lead to an increase in complications in clinical practice. The leading cause of death in thalassaemia patients is cardiac-related complications, and small differences in SFC and LIC are not predictors of such events [22]. In contrast, cardiac MRI T2* has been shown to have a high predictive value for heart failure and a strong correlation with iron-induced heart disease in studies by Kirk et al. [22] and Carpenter et al. [68]. The limitations around efficacy assumptions could be resolved by performing an indirect comparison using the available trial data. Such an evaluation was outside the scope of the current analysis, but would be desirable for any future studies.

Other limitations include the use of cost per mg for each regimen and the lack of national set NHS prices for laboratory tests. Using cost per mg may be a limitation as this assumes that tablets or vials may be halved or shared. While this may not be the case in clinical practice, this is a limitation inherent to the majority of economic models using an average dose per patient. This is therefore unlikely to have a significant impact upon the validity of the results. Due to the lack of a national set NHS price list for laboratory tests, it was necessary to use costs obtained through internal costing exercises provided by the Quality Manager at the Department of Laboratory Haematology at the John Radcliffe Hospital, Oxford (personal communication). These internal exercises are designed to provide the hospital with a best estimate of the cost of laboratory tests, based on variables including consumable use and personnel costs. The John Radcliffe Hospital is a large UK institution; as its estimated costs are likely to be comparable to those in other similarly sized NHS trusts, it represents an appropriate source of information in the absence of set NHS prices. While there is no guarantee that these costs are generalizable, there is no evidence that they are not. These costs also comprise only a small proportion of total costs and therefore have a minimal effect on the model results.

The other main limitation of the model is the use of all treatment regimens in the same population. All three iron chelators have different indications in their SPCs; DFO is indicated for all patients [12], DFX is indicated for all patients $\geq 6$ years old, or patients aged $2-5$ years in whom DFO is contraindicated or inadequate [17], while DFP is indicated for all patients in whom DFO is contraindicated or inadequate [15]. While these represent different populations, guidelines on the treatment of $\beta$-thalassaemia indicate that regimens should be tailored to the needs of the patient, rather than limiting their use to specific populations [5]. For example, DFP and DFX monotherapy are both recommended when adherence to DFO therapy is a concern, with DFP specifically recommended in patients with potentially dangerous cardiac iron levels [5]. Combination therapy may be recommended in patients with high SFC and LIC levels and 'normal' cardiac iron levels [5]. Treatment choices are therefore dependent on the likelihood of compliance and the combination of SFC, LIC and cardiac MRI T2*. Given the complexity of modelling these different situations, and the absence of data to inform such a model, it was consequently decided to use the overall patient population.

The perspective used in the model was that of the UK NHS, including personal and social services. The societal perspective was not used due to a lack of data on productivity gains/losses or absenteeism with the various treatment regimens, and the consequent difficulty in quantifying their effect on these outcomes. However, it is highly likely that cardiac morbidity and mortality would be the main factors influencing productivity in the $\beta$-thalassaemia population. As DFP has been shown to significantly improve cardiac morbidity and mortality compared with DFO [15], the exclusion of the societal perspective is likely to bias the analysis against DFP.

The results of this study are consistent with an economic model by Luangasanatip et al. [30], which evaluated the cost effectiveness of DFP, DFX and DFO from a Thai perspective. The analysis was performed using a Markov model, as in the current analysis, and the same values were used for the QoL decrement associated with DFO administration [30]. In the Thai study it was assumed that DFP, DFX and DFO had equivalent efficacy for all outcomes; however, the results indicated that DFP still dominated DFX and DFO, as was found in our analysis.

Three other studies have examined the cost effectiveness of DFX relative to DFO, two of which excluded DFP monotherapy from the analysis [3, 28, 29]. Given that DFP is likely to be used in a similar population in clinical 
practice, the exclusion of DFP in these studies means that they do not represent the true cost effectiveness of the interventions considered. These studies assumed that DFX and DFO have equivalent efficacy, as in our analysis, but did not include published AE rates. Karnon et al. [28] found that DFX dominated DFO over a 1-year period in their base case (mean patient weight $42 \mathrm{~kg}$ ), and resulted in an ICER of $£ 7,775$ when mean patient weight was assumed to be $62 \mathrm{~kg}$. A later study by Karnon et al. [29] considered cost effectiveness over a lifetime, using the assumption that the increased compliance afforded by oral treatment would lead to a survival benefit. AEs were considered in the analysis by Karnon et al., although rates for these were not obtained from published literature, but were simulated based on expected compliance. The Karnon study found that DFX gave a cost saving of $£ 72,089$ over a patient lifetime compared with DFO; however, the use of modelled $\mathrm{AE}$ rates and an inferred survival benefit are not as robust as those used in the current analysis, where published evidence was used. Despite this, the sensitivity analyses performed in the Karnon et al. [29] study resulted in a maximum ICER of $£ 12,166$, indicating that DFX is still likely to be cost effective over a lifetime, compared with DFO. The current analysis found that DFP dominated both DFX and DFO over a 5-year period, and would therefore most likely result in cost savings against both DFX and DFO over a patient lifetime, although this was not modelled.

McLeod et al. [3] evaluated DFX, DFO and DFP in a simple model as part of a UK HTA in all conditions requiring regular transfusions, using a 1-year time horizon. This group found that DFX was likely to be cost effective compared with DFO, with an ICER of $\leq £ 30,000$ per QALY. DFP was not assumed to provide any additional health benefits; however, in the analysis where it was assumed that DFP and DFX had equivalent efficacy, it was found that DFX was not cost effective for any patient compared with DFP [3]. Although this model considered all three iron chelators, it did not compare DFP with DFO, did not evaluate combination therapy, and used a much broader patient population than the current model. Despite this, the finding that DFP is cost effective compared with DFX is consistent with the conclusions from the current study.

The results of this analysis are specific to the UK NHS; however, they are likely to be applicable in most countries. It is highly unlikely that the efficacy of the available regimens, the utility associated with their administration, or the incidence of AEs would vary between countries. In contrast, the costs associated with each regimen (including drug costs, management of AEs, and monitoring) would be expected to vary. However, as DFP generated more QALYs than DFO, DFX or DFO-DFP, it will always be the dominant strategy unless it is more expensive than the other treatment regimens. It is therefore likely that the results of the model would be relevant in any countries where DFP is less expensive than DFX (or priced similarly to DFO).

The results of this analysis indicate that, from a UK perspective, DFP monotherapy dominates DFX and DFO monotherapy and combination therapy over a 5-year time horizon. DFP is currently indicated for use in all patients when DFO is inadequate; however, the high QoL burden associated with DFO administration [13] and the consequent implications for compliance mean that DFO therapy may be inadequate for many patients. Adopting DFP in these patients has been shown to confer a cardiac benefit [16, 19-21] and, as shown in the current analysis, it may also result in substantial cost savings compared with DFO and DFX.

\section{Conclusion}

DFP appears to be the dominant treatment strategy from a UK NHS perspective for chronic iron overload in $\beta$-thalassaemia patients; at a willingness-to-pay threshold of $£ 20,000$ per QALY, there is a $>99 \%$ probability of DFP being cost effective in all scenarios explored.

Acknowledgments The authors would like to thank Andrew Platt (Quality Manager, Department of Laboratory Haematology), Dr Paul Telfer (consultant haematologist), Prof. Sunil Bhandhari (consultant nephrologist), and Dr Farrukh Shah (consultant haematologist) for their assistance in validating the model inputs and assumptions. The authors would also like to thank Dr. Helen Dakin for her assistance in verifying the model structure, and Stephen Mitchell and Sjokvist Garcia-Stewart of Abacus International for performing the systematic review. This study was funded by ApoPharma Inc. The manuscript was prepared by Ewan Bennett of Abacus International.

Author roles All authors were involved in the conception and design of the study, and review of the manuscript. M. Spino, J. Connelly, and F. Tricta are employees of ApoPharma Inc. A. Bentley and S. Gillard are employees of Abacus International.

Open Access This article is distributed under the terms of the Creative Commons Attribution Noncommercial License which permits any noncommercial use, distribution, and reproduction in any medium, provided the original author(s) and the source are credited.

\section{References}

1. Modell B, Darlison M. Global epidemiology of haemoglobin disorders and derived service indicators. Bull World Health Organ. 2008;86:480-7.

2. Higgs D, Engel J, Stamatoyannopoulos G. Thalassaemia. Lancet. 2012;379(9813):373-83.

3. McLeod C, Fleeman N, Kirkham J, Bagust A, Boland A, Chu P, et al. Deferasirox for the treatment of iron overload associated 
with regular blood transfusions (transfusional haemosiderosis) in patients suffering with chronic anaemia: a systematic review and economic evaluation. Health Technol Assess 2009;13(1)(iii-iv, ix-xi): $1-121$.

4. Galanello R, Origa R. Beta-thalassemia. Orphanet J Rare Dis. 2010;5(11).

5. UK Thalassaemia Society. Standards for the clinical care of children and adults with thalassaemia in the UK [online]. http://sct. screening.nhs.uk/cms.php?folder=2493 [Accessed 19 Feb 2013].

6. Modell B, Khan M, Darlison M, Westwood M, Ingram D, Pennell D. Improved survival of thalassaemia major in the UK and relation to T2* cardiovascular magnetic resonance. J Cardiovasc Magn Reson 2008;10:42.

7. Gabutti V, Borgna-Pignatti C. Clinical manifestations and therapy of transfusional haemosiderosis. Clin Haematol. 1994;7(4):919-40.

8. Borgna-Pignatti C, Rugolotto S, De Stefano P, Zhao H, Cappellini M, Del Vecchio G, et al. Survival and complications in patients with thalassemia major treated with transfusion and deferoxamine. Haematologica. 2004;89(10):1187-93.

9. Cunningham M, Macklin E, Neufeld E, Cohen A. Complications of beta-thalassemia major in North America. Blood. 2004; 104(1):34-9.

10. Modell B, Khan M, Darlison M. Survival in beta-thalassaemia major in the UK: data from the UK Thalassaemia Register. Lancet. 2000;355(9220):2051-2.

11. Zurlo M, De Stefano P, Borgna-Pignatti C, Di Palma A, Piga A, Melevendi C, et al. Survival and causes of death in thalassaemia major. Lancet. 1989;2(8653):27-30.

12. Novartis Pharmaceuticals. Desferal SPC [online]. http://www. medicines.org.uk/EMC/medicine/2666/SPC/Desferal+Vials\% $2 \mathrm{c}+500 \mathrm{mg}+\mathrm{or}+2 \mathrm{~g} /$ [Accessed $19 \mathrm{Feb}$ 2013]

13. Abetz L, Baladi J-F, Jones P, Rofail D. The impact of iron overload and its treatment on quality of life: results from a literature review. Health Qual Life Outcomes. 2006;4:73.

14. Delea T, Edelsberg J, Sofrygin O, Thomas S, Baladi J-F, Phatak $\mathrm{P}$, et al. Consequences and costs of noncompliance with iron chelation therapy in patients with transfusion-dependent thalassemia: a literature review. Transfusion. 2007;47(10):1919-29.

15. European Medicines Agency. Ferriprox: EPAR - product information [online]. http://www.ema.europa.eu/ema/index.jsp?curl= pages/medicines/human/medicines/000236/human_med_000789. jsp\&mid=WC0b01ac058001d124 [Accessed 19 Feb 2013].

16. Borgna-Pignatti C, Cappellini M, De Stefano P, Del Vecchio G, Forni G, Gamberini M, et al. Cardiac morbidity and mortality in deferoxamine- or deferiprone-treated patients with thalassemia major. Blood. 2006;107(9):3733-7.

17. European Medicines Agency. Exjade: EPAR - Product Information [online]. http://www.ema.europa.eu/ema/index.jsp?curl= pages/medicines/human/medicines/000670/human_med_000780. jsp\&mid=WC0b01ac058001d124 [Accessed 19 Feb 2013].

18. Maggio A, D'Amico G, Morabito A, Capra M, Ciaccio C, Cianciulli $\mathrm{P}$, et al. Deferiprone versus deferoxamine in patients with thalassemia major: a randomized clinical trial. Blood Cells Mol Dis. 2002;28(2):196-208.

19. Pennell D, Berdoukas V, Karagiorga M, Ladis V, Piga A, Aessopos A, et al. Randomized controlled trial of deferiprone or deferoxamine in beta-thalassemia major patients with asymptomatic myocardial siderosis. Blood. 2006;107(9):3738-44.

20. Berdoukas V, Chouliaras G, Moraitis P, Zannikos K, Berdoussi E, Ladis V. The efficacy of iron chelator regimes in reducing cardiac and hepatic iron in patients with thalassaemia major: a clinical observational study. J Cardiovasc Magn Reson. 2009; 11:20.

21. Pepe A, Meloni A, Capra M, Cianciulli P, Prossomariti L, Malaventura $\mathrm{C}$, et al. Deferasirox, deferiprone and desferrioxamine treatment in thalassemia major patients: cardiac iron and function comparison determined by quantitative magnetic resonance imaging. Haematologica. 2011;96(1):41-7.

22. Kirk P, Roughton M, Porter J, Walker J, Tanner M, Patel J, et al. Cardiac T2* magnetic resonance for prediction of cardiac complications in thalassemia major. Circulation. 2009;120(20):1961-8.

23. Pennell D, Carpenter J, Roughton M, Cabantchik Z. On improvement in ejection fraction with iron chelation in thalassemia major and the risk of future heart failure. J Cardiovasc Magn Reson. 2011;13:45.

24. Farmaki K, Tzoumari I, Pappa C, Chouliaras G, Berdoukas V. Normalisation of total body iron load with very intensive combined chelation reverses cardiac and endocrine complications of thalassaemia major. Br J Haematol. 2010;148(3):466-75.

25. Tanner MA, Galanello R, Dessi C, Smith GC, Westwood MA, Agus A, et al. A randomized, placebo-controlled, double-blind trial of the effect of combined therapy with deferoxamine and deferiprone on myocardial iron in thalassemia major using cardiovascular magnetic resonance. Circulation. 2007;115(14):1876-84.

26. Hoffbrand A, Cohen A, Hershko C. Role of deferiprone in chelation therapy for transfusional iron overload. Blood. 2003;102(1):17-24.

27. Ceci A, Mangiarini L, Felisi M, Bartoloni F, Ciancio A, Capra M, et al. The management of iron chelation therapy: preliminary data from a national registry of thalassaemic patients. Anemia. Epub 2011 Jun 05.

28. Karnon J, Tolley K, Oyee J, Jewitt K, Ossa D, Akehurst R. Costutility analysis of deferasirox compared to standard therapy with desferrioxamine for patients requiring iron chelation therapy in the United Kingdom. Curr Med Res Opin. 2008;24(6):1609-21.

29. Karnon J, Tolley K, Vieira J, Chandiwana D. Lifetime costutility analyses of deferasirox in beta-thalassaemia patients with chronic iron overload: a UK perspective. Clin Drug Investig. 2012;32(12):805-15. doi:10.1007/s40261-012-0008-2.

30. Luangasanatip N, Chaiyakunapruk N, Upakdee N, Wong P. Ironchelating therapies in a transfusion-dependent thalassaemia population in Thailand: a cost-effectiveness study. Clin Drug Investig. 2011;31(7):493-505.

31. Cappellini M, Cohen A, Piga A, Bejaoui M, Perrotta S, Agaoglu L, et al. A phase 3 study of deferasirox (ICL670), a once-daily oral iron chelator, in patients with beta-thalassemia. Blood. 2006;107(9):3455-62.

32. Cohen A, Glimm E, Porter J. Effect of transfusional iron intake on response to chelation therapy in beta-thalassemia major. Blood. 2008;111(2):583-7.

33. Galanello R, Kattamis A, Piga A, Fischer R, Leoni G, Ladis V, et al. A prospective randomized controlled trial on the safety and efficacy of alternating deferoxamine and deferiprone in the treatment of iron overload in patients with thalassemia. Haematologica. 2006;91(9):1241-3.

34. Maggio A, Vitrano A, Capra M, Cuccia L, Gagliardotto F, Filosa A, et al. Improving survival with deferiprone treatment in patients with thalassemia major: a prospective multicenter randomised clinical trial under the auspices of the Italian Society for Thalassemia and Hemoglobinopathies. Blood Cells Mol Dis. 2009;42(3):247-51.

35. Maggio A, Vitrano A, Capra M, Cuccia L, Gagliardotto F, Filosa A, et al. Long-term sequential deferiprone-deferoxamine versus deferiprone alone for thalassaemia major patients: a randomized clinical trial. Br J Haematol. 2009;145(2):245-54.

36. Modell B, Letsky E, Flynn D, Peto R, Weatherall D. Survival and desferrioxamine in thalassaemia major. $\mathrm{Br}$ Med $\mathrm{J}$. 1982;284(6322):1081-4.

37. Nisbet-Brown E, Olivieri N, Giardina P, Grady R, Neufeld E, Séchaud R, et al. Effectiveness and safety of ICL670 in ironloaded patients with thalassaemia: a randomised, double-blind, placebo-controlled, dose-escalation trial. Lancet. 2003; 361(9369):1597-602. 
38. Piga A, Galanello R, Forni G, Cappellini M, Origa R, Zappu A, et al. Randomized phase II trial of deferasirox (Exjade, ICL670), a once-daily, orally-administered iron chelator, in comparison to deferoxamine in thalassemia patients with transfusional iron overload. Haematologica. 2006;91(7):873-80.

39. Ceci A, Baiardi P, Felisi M, Cappellini MD, Carnelli V, De Sanctis V, et al. The safety and effectiveness of deferiprone in a large-scale, 3-year study in Italian patients. $\mathrm{Br} \mathrm{J}$ Haematol. 2002;118(1):330-6.

40. Cohen A, Galanello R, Piga A, DiPalma A, Vullo C, Tricta F. Safety profile of the oral iron chelator deferiprone: a multicentre study. Br J Haematol. 2000;108(2):305-12.

41. Cohen AR, Galanello R, Piga A, De Sanctis V, Tricta F. Safety and effectiveness of long-term therapy with the oral iron chelator deferiprone. Blood. 2003;102(5):1583-7.

42. Ladis V, Chouliaras G, Berdoukas V, Moraitis P, Zannikos K, Berdoussi E, et al. Relation of chelation regimes to cardiac mortality and morbidity in patients with thalassaemia major: an observational study from a large Greek Unit. Eur J Haematol. 2010;85(4):335-44.

43. Piga A, Gaglioti C, Fogliacco E, Tricta F. Comparative effects of deferiprone and deferoxamine on survival and cardiac disease in patients with thalassemia major: a retrospective analysis. Haematologica. 2003;88(5):489-96.

44. El Alfy M, Sari T, Lee C, Tricta F, El-Beshlawy A. The safety, tolerability, and efficacy of a liquid formulation of deferiprone in young children with transfusional iron overload. J Pediatr Hematol Oncol. 2010;32(8):601-5. doi:10.1097/MPH.0b013e3181ec0f13.

45. National Institute for Health and Clinical Excellence. Guide to the methods of technology appraisal (2008) [online]. http://www. nice.org.uk/media/B52/A7/TAMethodsGuideUpdatedJune2008. pdf [Accessed 19 Feb 2013].

46. HM Treasury. Green Book: appraisal and evaluation in central government; 2003.

47. Miller D, Homan S. Determining transition probabilities: confusion and suggestions. Med Decis Making. 1994;14(1):52-8.

48. The Institute for Safe Medication Practices. QuarterWatch: 2009 Quarter 4.

49. Apotex Inc. Briefing book for the Ferriprox Advisory Committee [online]. http://www.fda.gov/AdvisoryCommittees/Committees MeetingMaterials/Drugs/OncologicDrugsAdvisoryCommittee/ ucm271469.htm [Accessed 19 Feb 2013].

50. Novartis Pharmaceuticals. Exjade ${ }^{\circledR}$ US Prescribing Information.

51. Yacobovich J, Stark P, Barzilai-Birenbaum S, Krause I, Pazgal I, Yaniv I, et al. Acquired proximal renal tubular dysfunction in Bthalassemia patients treated with deferasirox. J Pediatr Hematol Oncol. 2010;32(7):564-7.

52. TUFTS cost-effectiveness analysis registry. https://research.tuftsnemc.org/cear4/SearchingtheCEARegistry/SearchtheCEARegistry. aspx.

53. Ossa D, Briggs A, Tafesse E, Iloeje U, Mukherjee J, LozanoOrtega G, et al. Impact on quality of life of health states induced by chronic hepatitis B infection: estimates from uninfected and infected persons in the UK. Poster presentation at the International Society for Pharmacoeconomics and Outcomes Research (ISPOR) 8th Annual European Congress, Florence; 2005 Nov 6-8.
54. Perlis R, Ganz D, Avorn J, Schneeweiss S, Glynn R, Smoller J, et al. Pharmacogenetic testing in the clinical management of schizophrenia: a decision-analytic model. J Clin Psychopharmacol. 2005;25(5):427-34.

55. Priest V, Begg E, Gardiner S, Frampton C, Gearry R, Barclay M, et al. Pharmacoeconomic analyses of azathioprine, methotrexate and prospective pharmacogenetic testing for the management of inflammatory bowel disease. PharmacoEconomics. 2006;24(8): 767-81.

56. BMJ Group. British National Formulary 63, London; 2012.

57. Apotex Inc. USA registry for enhanced pharmacovigilance of agranulocytosis in patients treated with Ferriprox ${ }^{\circledR}$, Toronto; 2013.

58. Curtis L. Unit costs of health and social care 2010. Canterbury: Personal Social Services Research Unit; 2010.

59. Department of Health. NHS Reference costs 2009/10 [online]. http://www.dh.gov.uk/en/Publicationsandstatistics/Publications/ PublicationsPolicyAndGuidance/DH_123459 [Accessed 19 Feb 2013].

60. Dakin H, Bentley A, Dusheiko G. Cost-utility analysis of tenofovir disoproxil fumarate in the treatment of chronic hepatitis B. Value Health. 2010;13(8):922-33.

61. Even-Or E, Becker-Cohen R, Miskin H. Deferasirox treatment may be associated with reversible renal Fanconi syndrome. Am J Hematol. 2010;85(2):132-4.

62. Grangé S, Bertrand D, Guerrot D, Eas F, Godin M. Acute renal failure and Fanconi syndrome due to deferasirox. Nephrol Dial Transplant. 2010;25(7):2376-8.

63. Rafat C, Fakhouri F, Ribeil J, Delarue R, Le Quintrec M. Fanconi syndrome due to deferasirox. Am J Kidney Dis. 2009;54(5): 931-4.

64. Rheault MN, Bechtel H, Neglia JP, Kashtan CE. Reversible Fanconi syndrome in a pediatric patient on deferasirox. Pediatr Blood Cancer. 2011;56(4):674-6.

65. Briggs A, Goeree R, Blackhouse G, O'Brien B. Probabilistic analysis of cost-effectiveness models: choosing between treatment strategies for gastroesophageal reflux disease. Med Decis Making. 2002;22(4):290-308.

66. Briggs AH. Handling uncertainty in cost-effectiveness models. PharmacoEconomics. 2000;17(5):479-500.

67. Pennell D, Porter J, Piga A, Lai Y, El-Beshlawy A, Beloul K, et al. A multicenter, randomized, open-label trial evaluating deferasirox compared with deferoxamine for the removal of cardiac iron in patients with $\beta$-thalassemia major and iron overload (CORDELIA) [abstract no.2124]. Blood. 2012;120:21.

68. Carpenter J-P, He T, Kirk P, Roughton M, Anderson L, de Noronha $\mathrm{S}$, et al. On T2* magnetic resonance and cardiac iron/ clinical perspective. Circulation. 2011;123(14):1519-28.

69. Department of Health. 2010-2011: payment by results National Tariff [online]. http://www.dh.gov.uk/en/Publicationsandstatistics/ Publications/PublicationsPolicyAndGuidance/DH_112284 [Accessed 19 Feb 2013].

70. County Pathology. Cost of tests [online]. http://www.county pathology.co.uk/Prices/Prices.html [Accessed 19 Feb 2013]. 